\title{
SISTEM PENDUKUNG KEPUTUSAN PENENTUAN INVESTASI KELAPA SAWIT DENGAN METODE INTERNAL RATE OF RETURN DALAM SATU BLOCK SAWIT DI LINGGA KUAMANG BUNGO JAMBI
}

\author{
Bambang Sudibyo, Joko Suismianto \\ Program Studi Teknik Informatika \\ Sekolah Tinggi Teknologi Adisutjipto Yogyakarta \\ informatika@,stta.ac.id
}

\begin{abstract}
Technology developed in order to facilitate human work that would not be done manually, with the presence of the latest technologies that it is not a work of man may not be done quickly, accurately, and save time. One was for the mamufacture of palm data processing applications that provide an overview to the public that it is feasible to plant palm oil or not to do, based on existing data and then recycled into Decision Support Systems. To process these data using the Internal Rate Of Return (IRR) as a method to make decisions based on data that have been processed. In this study processed data is the data of a group of Palm Jl. Salak Linga Kuamang Bungo Jambi. From the results of the data managed by the farmer group Palm block 22, Jalan Salak, Linga Kuamang, with interpolation of 30\% per year, with a capital of USD 888,253,000.00 and generate income of $R p$ 2,063,387,050.00 in if using the Internal rate of Return produce interpolation (I) of $30,113 \%$. Since IRR $>I$, then it is worth to continue.
\end{abstract}

Keywords : DSS, Internal Rate Of Return, Palm Oil.

\section{Pendahuluan}

Teknologi dikembangkan dengan tujuan mempermudah pekerjaan manusia yang kiranya tidak bisa dikerjakan secara manual, dengan hadirnya teknologi-teknologi yang terbaru maka tidaklah tidak mungkin suatu pekerjaan manusia dapat dikerjakan degan cepat, akurat, dan menghemat waktu.Salah satu yang menggunakan teknologi tersebut adalah kelompok tani Kelapa Sawit block 22 Jalan Salak, Lingga Kuamang, Pelepat Ilir, Bungo, Jambi. Kelompok tani tersebut menyimpan data-data mengenai kelapa sawit pada sebuah Komputer. Namun data dari hasil pemanenan, perawatan, dan penanaman hanya disimpan begitu saja dan tidak digunakan atau diolah kembali. Data tersebut hanya tersimpan di sebuah database kelompok tani tersebut.Melihat permasalahan pada kelompok tani tersebut adalah menumpuknya data-data yang sebenarnya bisa diolah menjadi sebuah informasi baru dan bermanfaat salah satunya adalah menentukan sistem pendukung keputusan kelayakan menanam kelapa sawit dengan mengolah data-data yang ada.

\section{Kajian Pustaka}

Penelitian terdahulu menjadi salah satu bahan referensi untuk menggali informasi mengenai materi-materi yang berkaitan dalam tugas akhir. Penelitian-penelitian yang memiliki hubungan tersebut adalah dalam jurnalnya yang di tulis oleh Ermi Tety, Sakti Hutabarat, Fajar Manggala Putra (2012), yang berjudulprospek komoditas minyak kelapa sawit (cpo) dalam pengembangan biodiesel sebagai alternatif bahan bakar di Indonesia. Dalam jurnalnya menjelaskan bahwasektor pertanian selain sebagai produsen energi terbarukan juga sebagai investasi jangka panjang yang menjajikan. Terlepas dari titik penjualan yang cukup kompetitif, biodiesel juga dianggap ramah lingkungan dan energi terbarukan karena menggunakan bahan baku dari produk budidaya pertanian. Selama periode lima tahun di mana harga minyak melambung, harga biodiesel lebih 
rendah dengan substitusi produk minyak bumi dan potensi dan layak untuk diproduksi. Hasil NPV (Rp 44,7 miliar) dan IRR (38.94\%) dalam penelitian ini menunjukkan kelayakan produksi biodiesel.

\section{Metode Penelitian}

\subsection{Sistem Pendukung Keputusan}

Sistem pendukung keputusan dapat digambarkan sebagai "sistem yang berkemampuan mendukung analisis adhoc data, dan pemodelan keputusan, berorientasi keputusan, orientasi perencanaan masa depan dan digunakan pada saat-saat yang tidak biasa". Dalam sistem pakar mempunyai banyak metode seperti metode AHP, Internal Rate of Return (IRR), Net Present Value (NPV), Benefit Cost Ratio (BCR), Fuzzy, Gap dan lainnya. Dari berbagai metode tersebut, dalam pengolahan data kelapa sawit memilih menggunakan metode Internal Rate of Return.

Tujuan dari SPK:

1. Membantu menyelesaikan masalah semi-terstruktur

2. Mendukung manajer dalam mengambil keputusan

3. Meningkatkan efektifitas bukan efisiensi pengambilan keputusan

\subsection{Internal Rate Of Return}

IRR berasal dari bahasa Inggris Internal Rate of Return disingkat IRR yang merupakan indikator tingkat efisiensi dari suatu investasi. Suatu proyek/investasi dapat dilakukan apabila laju pengembaliannya (rate of return) lebih besar dari pada laju pengembalian apabila melakukan investasi di tempat lain. Tingkat investasi adalah suatu tingkat bunga di mana seluruh net cash flow setelah dikalikan discountfactor atau telah di-present value-kan, nilainya samadengan initial investment (biaya invetasi).Kriteria kelayakan investasi dengan metode Internal Rate of Return (IRR) adalah dengan membandingkan nilai IRR dengan tingkat bunga yang berlaku pada saat ini seperti berikut :

Apabila IRR > I (Bunga modal), investasi layak.

Apabila IRR < I (Bunga modal), investasi tidak layak.

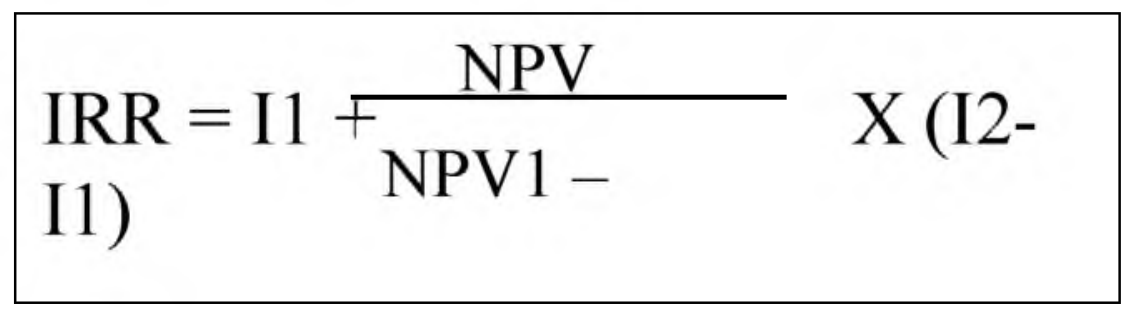

Gambar 1 rumus untuk mencari nilai IRR 


\subsection{Perancangan Sistem}

\subsubsection{Flowchart}

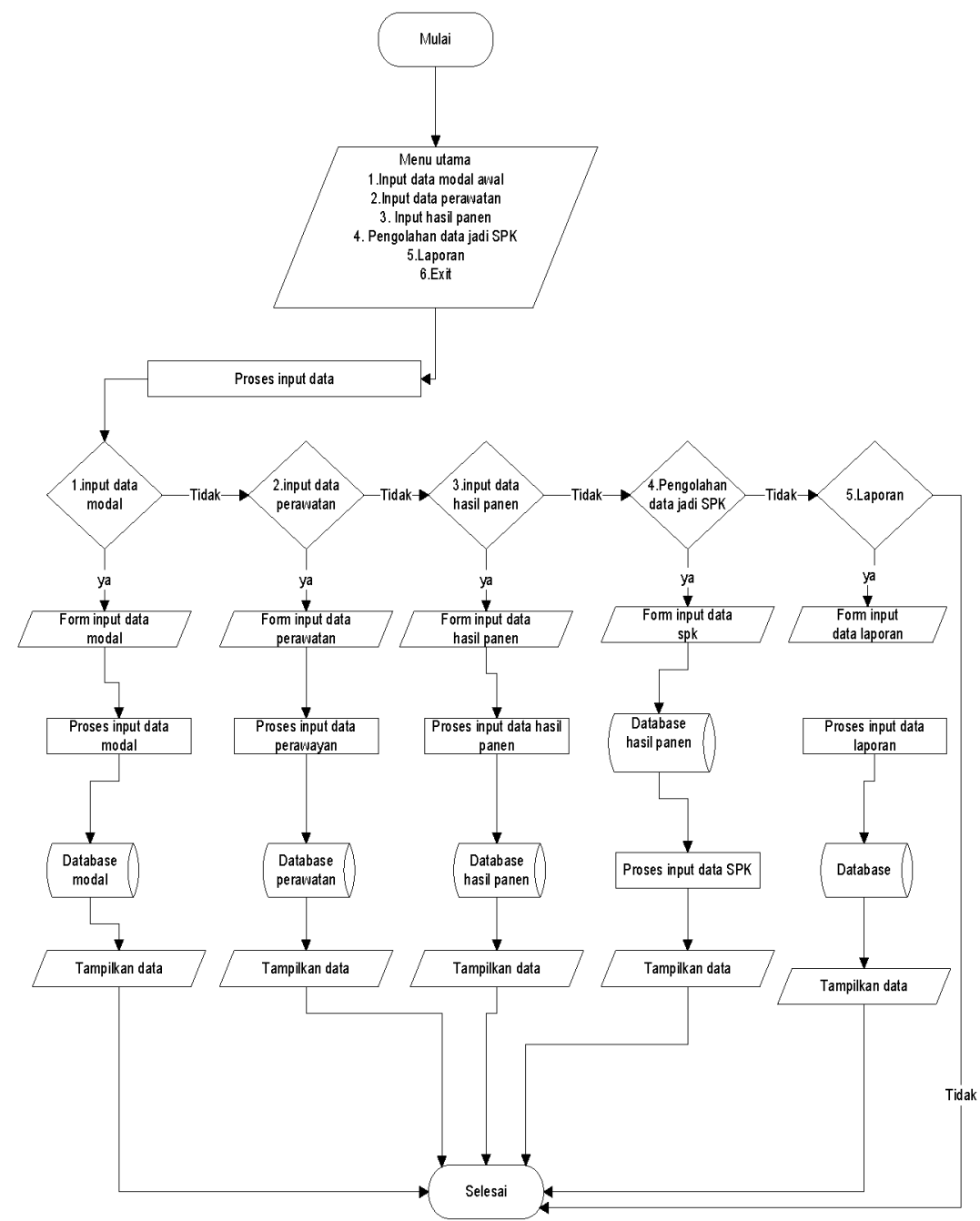

Gambar 2 Flowchart sistem pengolahan data kelapa sawit.

Sistem flowchart dapat didefinisikan sebagai bagan yang menunjukkan arus pekerjaan secara keseluruhan dari sistem. Bagan ini menjelaskan urut-urutan dari prosedur-prosedur yang ada di dalam sistem. Bagan alir sistem menunjukkan apa yang dikerjakan di sistem. Flowchart pengolahan data kelapa sawit dapat dilihat pada Gambar 2.

\subsubsection{Perancangan Relasi Antar Tabel}

Pembuatan relasi antar tabel bertujuan untuk membuat hubungan antar tabel agar ada relasi antara tabel yang satu dengan yang lain. Dapat dilihat pada Gambar 3 


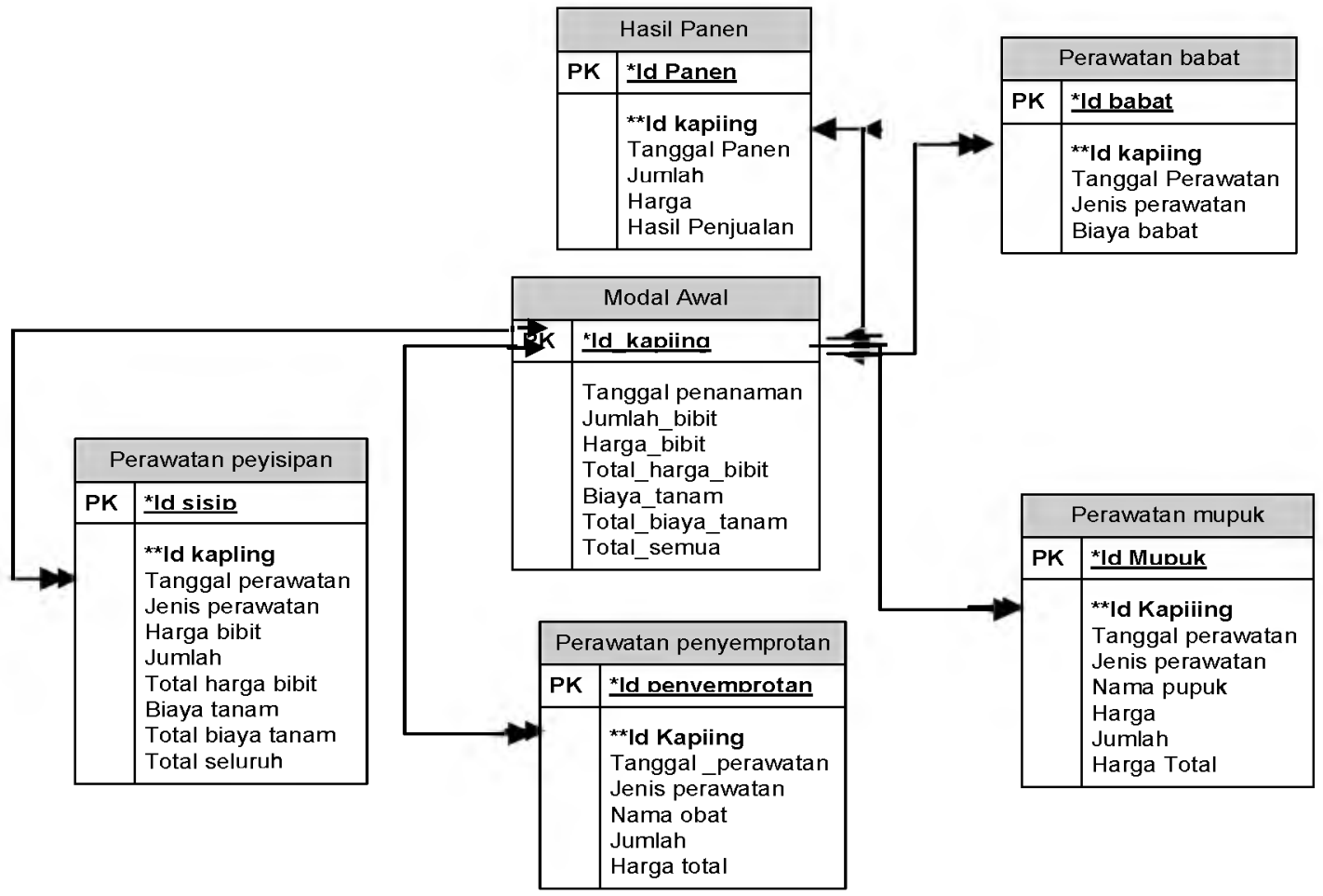

Gambar 3 Relasi Antar Tabel

\subsubsection{Perancangan Antarmuka}

Perancangan antar muka ini digunakan sebagai gambaran atau desain dalam membuat aplikasi system pendukung keputusan yang akan dibuat.Perancangan form menu utama adalah form yang terdapat beberapa sub menu di antaranya data modal awal, data perawatan, data hasil panen, dan pengolahan data menjadi SPK (Sistem Pendukung Keputusan). Berikut rancangan menu utama dapat dilihat pada Gambar 4.

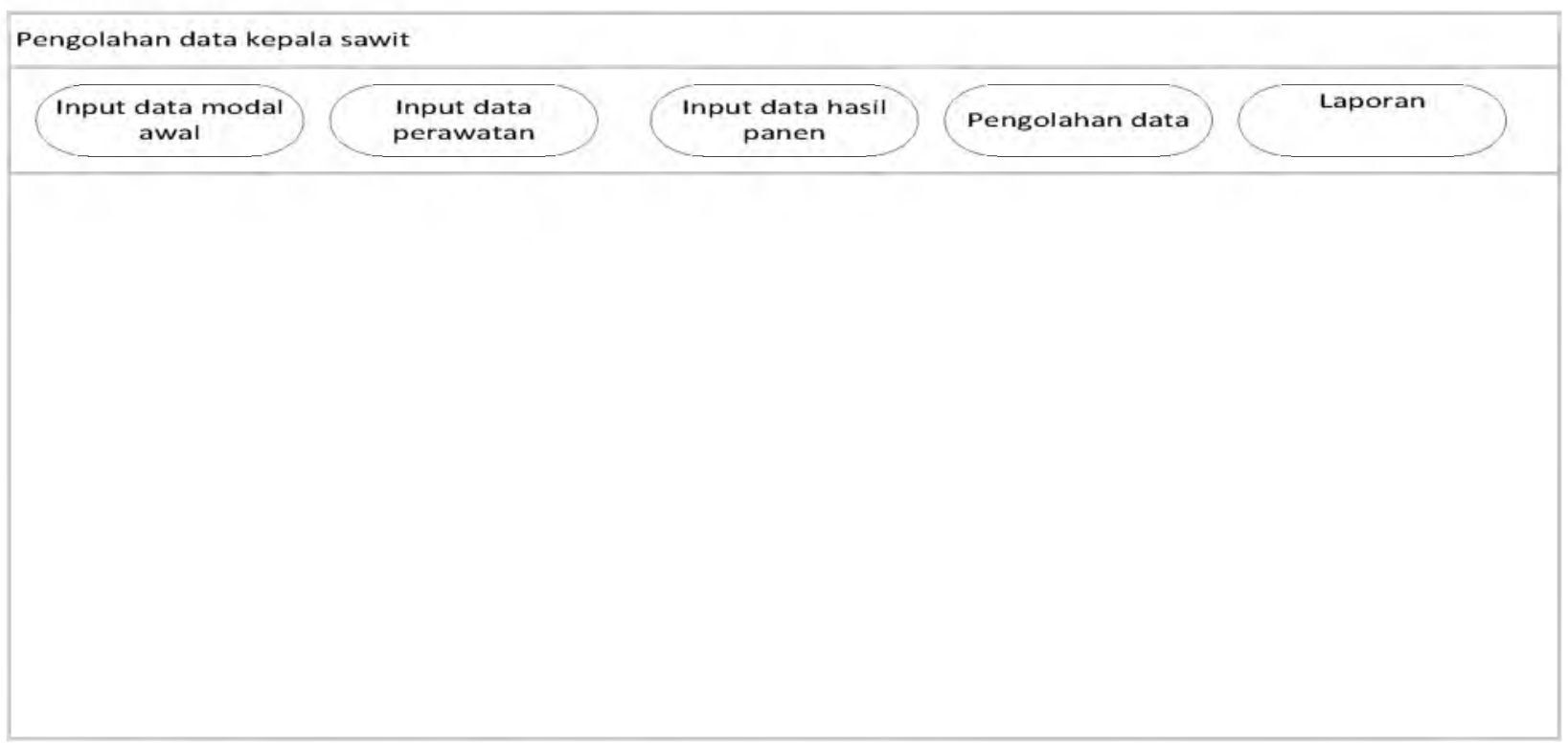

Gambar 4 Rancangan form menu utama pengolahan data menjadi SPK 
Perancangan form ini digunakan sebagai menu untuk menentukan SPK (Sistem Pendukung Keputusan). Rancangan form pengolahan data menjadi SPK (Sistem Pendukung Keputusan) dapat dilihat pada Gambar 5.

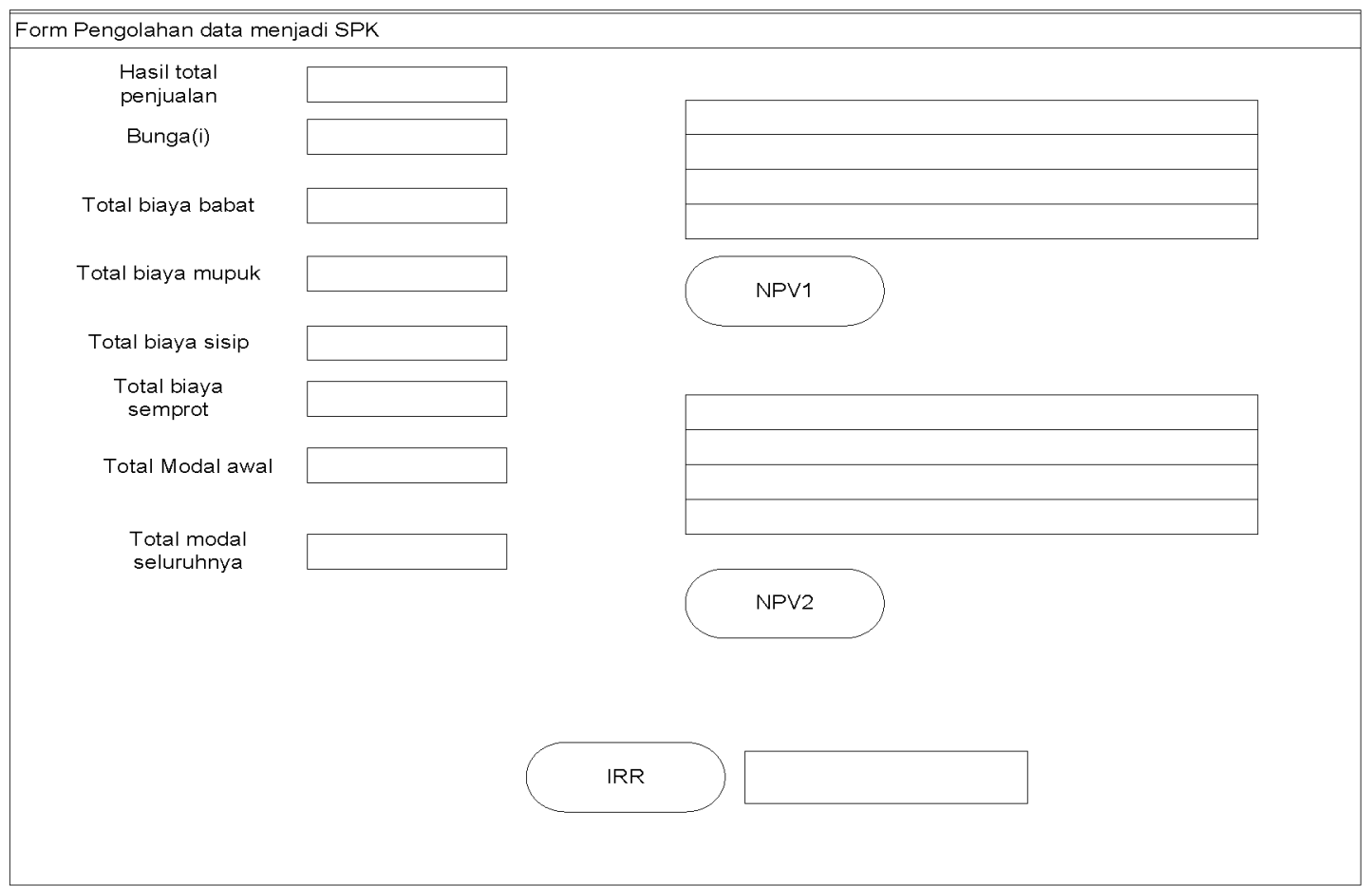

Gambar 5 Rancangan form menu pengolahan data menjadi SPK

\section{Hasil dan Pembahasan}

Implementasi sistem merupakan tahapan dimana sistem tersebut diletakkan setelah melalui perancangan sistem. Sehingga sistem tersebut siap untuk dioperasikan sesuai dengan yang diharapkan.

\subsection{Hasil}

Menu utama merupakan tampilan pertama kali saat aplikasi Sistem Pendukung Keputusan ini dijalankan. Dalam menu utama aplikasi ini terdapat beberapa menu di antaranya menu modal awal, hasil panen, perawatan, pengolahan data, dan laporan. Gambar menu utama aplikasi Sistem Pendukung Keputusan menentukan kelayakan menanam Kelapa Sawit bisa dilihat di Gambar 6. 


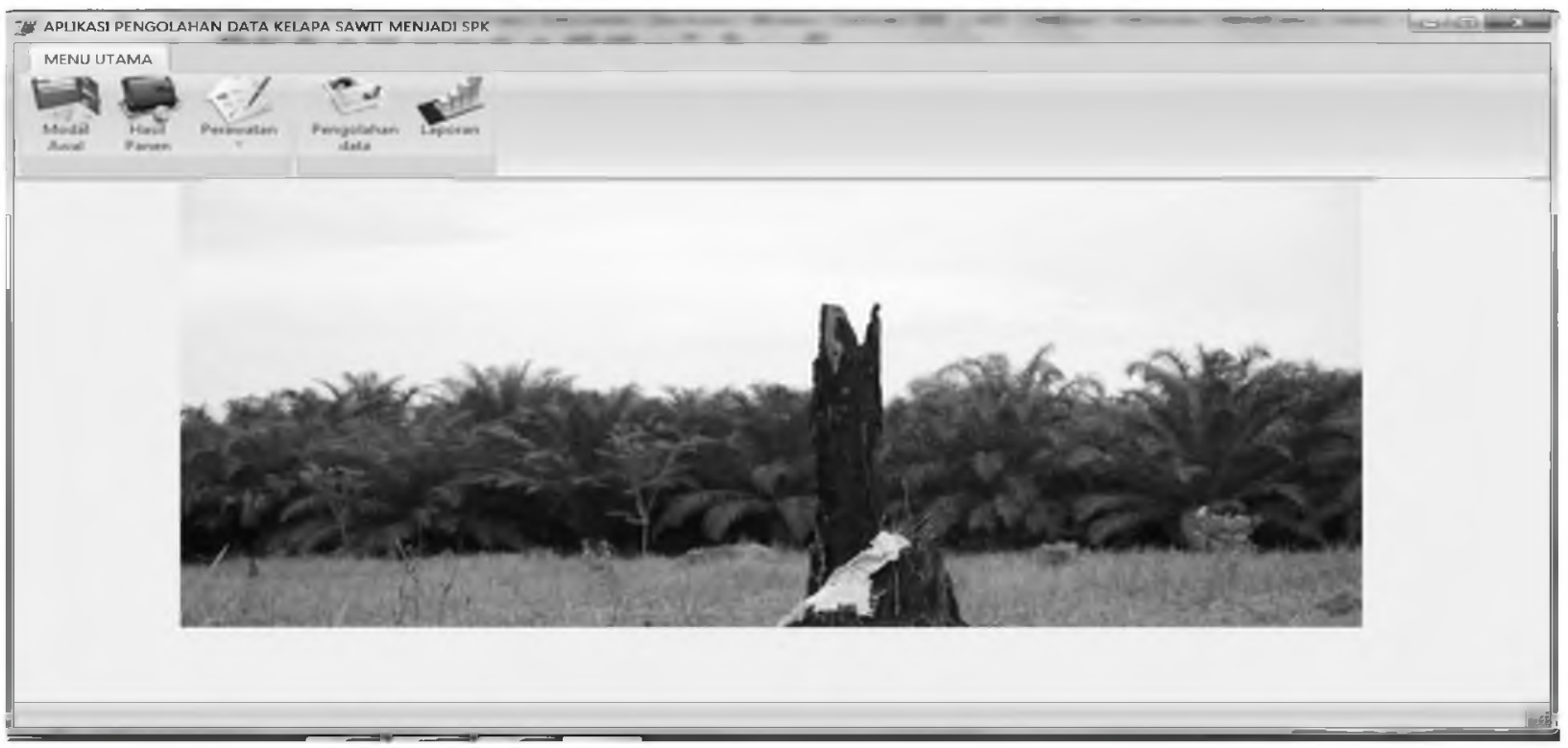

Gambar 6 implementasi menu utama

Tabel 1 Data kelapa sawit yang akan diolah.

\begin{tabular}{|l|c|c|c|c|c|c|}
\hline Thn & $\begin{array}{c}\text { Hasil } \\
\text { Penjualan } \\
(\mathrm{Rp})\end{array}$ & $\begin{array}{c}\text { Perawatan } \\
\text { babat } \\
\mathbf{R p}\end{array}$ & $\begin{array}{c}\text { Perawatan } \\
\text { semprot } \\
(\mathrm{Rp})\end{array}$ & $\begin{array}{c}\text { Perawatan } \\
\text { mupuk } \\
(\mathrm{Rp}\end{array}$ & $\begin{array}{c}\text { Perawatan } \\
\text { sisip } \\
(\mathrm{Rp})\end{array}$ & $\begin{array}{c}\text { Modal awal } \\
\text { (Rp) }\end{array}$ \\
\hline 2006 & - & 6.400 .000 & - & 35.920 .000 & - & 23.634 .000 \\
\hline 2007 & - & - & 6.750 .000 & 74.960 .000 & 10.763 .000 & - \\
\hline 2008 & - & 9.600 .000 & 14.902 .000 & 21.624 .0000 & - & - \\
\hline 2009 & - & - & 7.250 .000 & 72.509 .000 & - & - \\
\hline 2010 & - & - & 8.720 .000 & 75.818 .000 & - & - \\
\hline 2011 & 182.423 .345 & - & 5.310 .000 & 107.232 .000 & - & - \\
\hline 2012 & 813.888 .010 & - & 4.730 .000 & 92.640 .000 & - & - \\
\hline 2013 & 977.879 .395 & - & 5.250 .000 & 96.825 .000 & - & - \\
\hline 2014 & 89.196 .300 & - & - & - & - & - \\
\hline Total & 2.063 .387 .050 & 16.000 .000 & 65.712 .000 & 772.144 .000 & 10.763 .000 & 23.634 .000 \\
\hline
\end{tabular}

Tabel diatas merupakan tabel data kelapa sawit yang akan di olah. Data diambil mulai dari pertama menanam yaitu pada tahun 2006 hingga data tahun 2014, dimana tahun 2014 adalah terahir kali data diambil.Menu pengolahan data adalah menu yang berfungsi sebagi pengolah data yang kemudian hasil dari pengolahan data tersebut yang akan diambil sebagai penentuan pengambilan keputusan. Berikut adalah gambar dari tampilan hasil pengolahan data Kelapa Sawit dapat dilihat pada Gambar 7. 


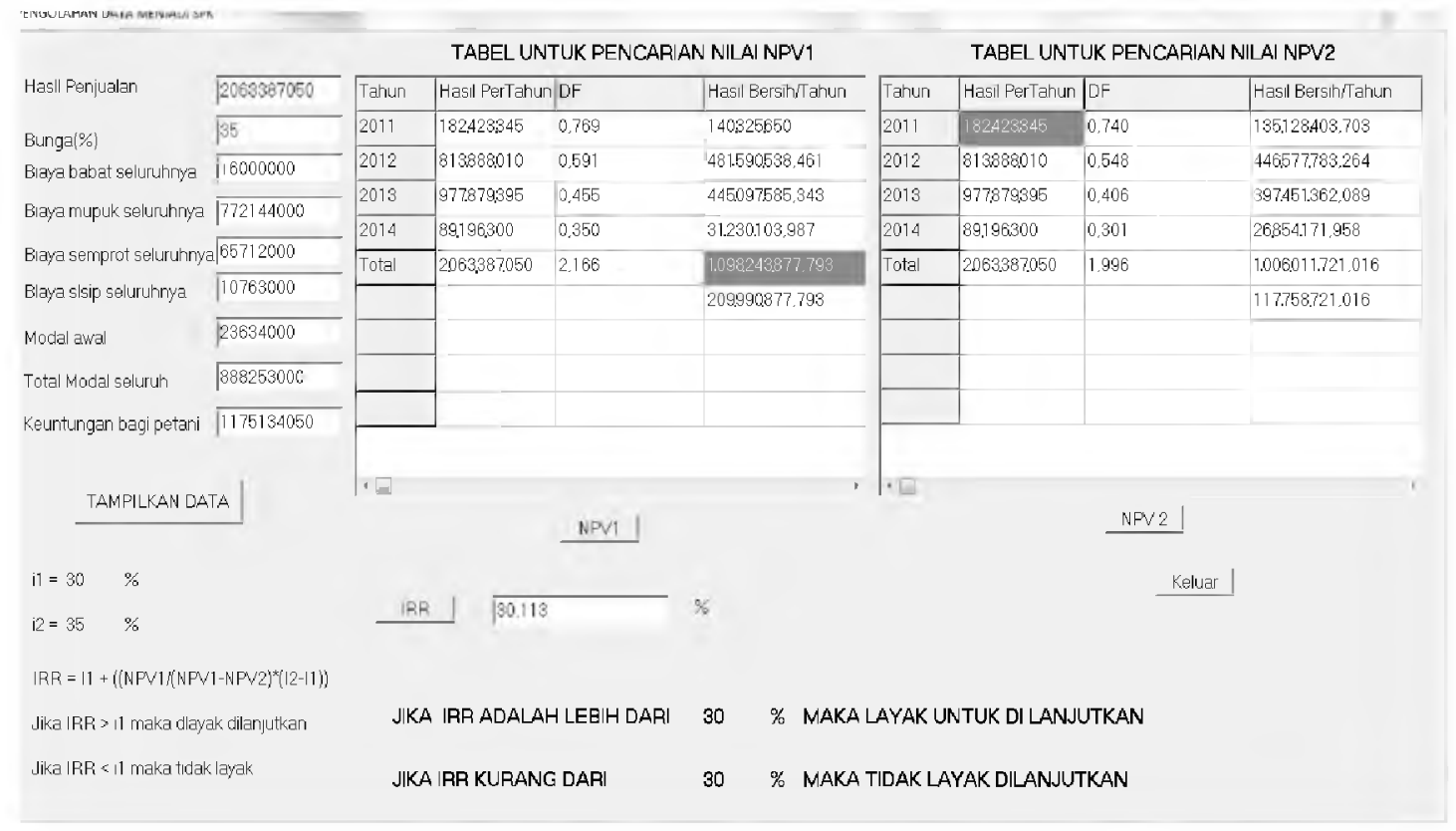

Gambar 7 Implementasi pengolahan data kelapa sawit menjadi SPK

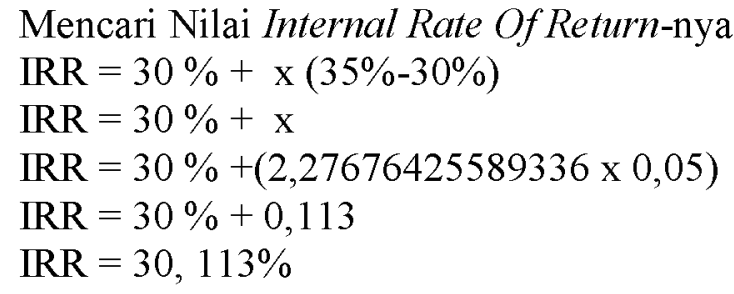

Dari hasil perhitungan di atas dengan perhitungan dalam aplikasi hasilnya adalah cocok atau sama dengan hasil di aplikasinya. Dengan ketentuan sebagai berikut.

IRR $>$ I maka layak untuk dilanjutkan.

IRR $<$ I maka tidak layak untuk dilanjutkan

Karena hasil Internal Rate of Return-nya adalah lebih dari 30\%, maka dapat simpulkan bahwa berdasarkan data-data yang telah di olah, penanaman kelapa sawit layak untuk dilanjutkan.

\section{Penutup}

\subsection{Kesimpulan}

Berdasarkan hasil dari tugas ahir yang meneliti tentang kelayakan penanaman Kelapa Sawit dengan data-data yang sudah ada, penulis mendapatkan beberapa kesimpulan sebagai berikut :

1. Dengan metode Internal Rate Of Return (IRR), menanam Kelapa Sawit layak untuk dilanjutkan berdasarkan data-data yang ada dan diolah dengan metode IRR tersebut.

2. Aplikasi yang dibuat ini dapat digunakan dalam pelaksanaan kegiatan pengolahan data Kelapa Sawit di block 22 Jl. Salak, Lingga Kuamang, menjadi lebih mudah dan lebih cepat sehingga dapat menghemat waktu.

3. Dengan total modal Rp.888.253.000,00 selama 4 tahun menghasilkan omset sebesar Rp.2.063.387.050,00 dan mendapat keuntungan sebesar Rp 1.175.134.050,00

\subsection{Saran}

Dalam analisis sistem dapat diketahui cara kerja sistem sehingga didapat saran-saran untuk pengembangan aplikasi ini selanjutnya. Saran-saran tersebut adalah Aplikasi ini bisa dikembangkan berbasis web, tujuannya adalah agar masyarakat yang ingin menanam Kelapa Sawit, bisa mengakses data-data tersebut dimanapun tempatnya, atau masyarakat yang sudah menanam tetapi 
ragu, mereka bisa memasukan data yang dimilikinya ke halaman web tersebut. Sistem dari web tersebut mengolah data yang dimasukan menjadi sebuah Sistem Pendukung Keputusan yang memberikan gambaran berdasarkan data yang dimasukan. Mereka bisa melihat dan mengambil kesimpulan bahwa menanam Kelapa Sawit tersebut layak atau tidak untuk dilakukan.

\section{Daftar Pustaka}

Bastian. Indra. 2007. Akuntansi Yayasan dan Lembaga Publik. Jakarta. Erlangga

Brigham. Houston. 2011. Buku I edisi 10 Dasar Dasar Manajement Keuangan (Revist). Jakarta. Salemba Empat

Hanafi. Mamduh.2005. Management Keuangan. Jogjakarta. BPFE UGM

Keown. Arthur J.. 2000. Dasar-Dasar Manajemen Keuangan, buku 2. Jakarta. Salemba Empat.

Abidin, A. Zainal. 2010. Mengetahui Besarnya Modal yang Dibutuhkan oleh PT Timurama Ujung Pandang dalam Membangun Perumahan, http://ois.umud.ac.id/index.php/Manaiemen/Jurnal (5 juli 2014)

Ermi Tety. Sakti Hutabarat. Fajar Manggala Putra.2012. Prospek Komoditas Minyak Kelapa Sawit (CPO) dalam Pengembangan Biodiesel sebagai Alternatif Bahan Bakar di Indonesia. http:/eiournal.unri.ac.id/index.php/JPEB/article/view/1469 (4 agustus 2014)

INTERNAL RATE OF RETURN (IRR)

http://1425w004.blogspot.com/internal-rate-of-return-irr.html (7 juli 2014) 